\title{
Study of Hawaii Geothermal opaline silica deposits with Raman, luminescence, NIR reflectance and $x-$ ray diffraction instruments
}

S.K. SHARMA ${ }^{1^{*}}$, D.M. THOMAS ${ }^{2}$, P. DERA, M.J. EGAN ${ }^{3}$, S. $\mathrm{LI}^{4}$, P.G. LUCEY ${ }^{5}$

All at Hawaii Institute of Geophysics and Planetology, Univ. of Hawaii at Manoa, Honolulu, HI-96822.USA

('Corresponding author: shiv@hawaii.edu)

Geothermal brine deposits of opaline silica $\left(\mathrm{SiO}_{2} \cdot \mathrm{nH}_{2} \mathrm{O}\right)$ have been used in the search of past life on Mars [1] and early Earth [2] because of their ability to capture and preserve biosignatutes. In 2007 the Mars Spirit rover found opaline silica adjacent to 'Home Plate' in Gusev crater on Mars [2]. Ruff and Farmer [3] proposed that terrestrial and Martian hydrothermal deposits of opaline silica originated from similar physical processes based upon comparison of thermal IR emission spectra.

The Mars 2020 rover instrument SuperCam includes time-resolved (TR) Raman, and laser-induced luminescence, and LIBS and near IR spectrometers that could provide confirmation about the nature of silica deposit on Mars. In this work, we have investigated opaline silica deposited by geothermal fluids from a geothermal well on the Island of Hawaii. We have used TR-Raman and luminescence spectroscopy in addition $\mathrm{x}$-ray diffraction and NIR reflectance spectroscopy to characterize the samples.

The presence of $\mathrm{Si}-\mathrm{OH}$ groups in the opaline silica is indicated by an additional Raman band at $967 \mathrm{~cm}^{-1}$ in the spectra[4]. The NIR reflectance of the samples show the prescence of both $\mathrm{OH}$ and $\mathrm{H}_{2} \mathrm{O}$ molecules in the samples. The TR-Raman and luminescence spectra show a very short-lived $(<10 \mathrm{~ns})$ luminescence indicating presence of organic or biological material [5]. The X-ray diffraction data confirmed amorphus nature of the opaline silica, and the bottom deposits as calcite, aragonite and halite. The results of these investigations will be presented at the conference.

[1] Walter et al. (1993) Icarus 101, 129-143. [2] Walter (1972) Econ. Geol. 67, 965-980. [3] Squyres, et al. (2008) Science 320, 1063-1067. [4] Ruff and Farmer (2016) Nat. Commun. 17, 13554/1-10. [5] McMillan and Remmele, Jr. (1986) Amer. Mineral. 71, 772-778. [6] Misra et al. (2016) Astrobiology, 16, 715-729. 